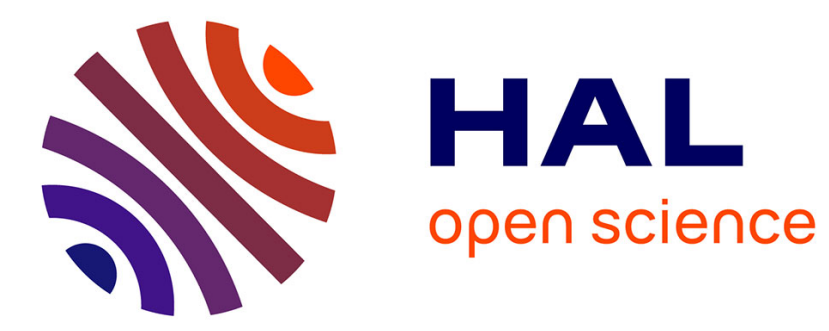

\title{
Can we believe what we do not understand?
}

François Recanati

\section{- To cite this version:}

François Recanati. Can we believe what we do not understand?. Mind and Language, 1997, 12 (1), pp.84-100. ijn_00000292

\section{HAL Id: ijn_00000292 \\ https://hal.science/ijn_00000292}

Submitted on 8 Nov 2002

HAL is a multi-disciplinary open access archive for the deposit and dissemination of scientific research documents, whether they are published or not. The documents may come from teaching and research institutions in France or abroad, or from public or private research centers.
L'archive ouverte pluridisciplinaire HAL, est destinée au dépôt et à la diffusion de documents scientifiques de niveau recherche, publiés ou non, émanant des établissements d'enseignement et de recherche français ou étrangers, des laboratoires publics ou privés. 


\title{
Can we believe what we do not understand?*
}

\author{
François Recanati \\ CREA \\ 1 rue Descartes \\ 75005 Paris, France
}

\section{Introduction: Sperber on quasi-belief}

Sometimes we believe things which we do not quite understand. To borrow an example from Dan Sperber, whose view I will present and discuss, Lacanians believe that the unconscious is structured like a language. They are not sure what this means, but they trust Lacan, who said so. This sort of 'belief' is important. It is involved in education, in religion, and in many other human activities. But it is rather different from what philosophers ordinarily call 'belief'. How different exactly? That is one of the questions I will try to answer in this paper. To avoid begging the question, I will use a technical term: 'quasi-belief'. The Lacanians, despite their uncertainty as to what Lacan means,

\footnotetext{
* I am grateful to Pascal Engel, who asked me to respond to Sperber in a conference on Belief and Acceptance (University of Caen, April 1995), and thereby initiated the process of writing this paper; to Michael Devitt who, at my request, sent me a copy of Donnellan's paper on deferential belief; and to Ned Block, Dick Carter, Reinaldo Elugardo, Pierre Jacob, Gloria Origgi, Dan Sperber, Andrew Woodfield, and a referee for this journal for their comments on earlier versions. See the postscript for more details concerning the origins of this paper.
} 
'quasi-believe' that the unconscious is structured like a language (i.e. they accept this sentence and are prepared to assert it, even though they do not fully understand it).

There are similar cases involving incomplete mastery of a public concept ('Burgean cases', as I will call them). Consider, for example, the representation that Cicero's prose is full of synecdoches, entertained by someone who has only a vague idea of what synecdoches are, but who trusts the teacher. The difference with the 'Lacanian' type of case is this: In the Lacanian case there is no publicly accepted interpretation for the sentence; opinions widely diverge concerning the correct interpretation. ${ }^{1}$ In contrast, there is a public interpretation of 'synecdoche', on which experts in rhetorics converge. Despite the difference, the two sorts of example have much in common. In both cases the subject accepts a sentence which she poorly understands, if she understands it at all.

In his book Rethinking Symbolism (Sperber 1975) Sperber distinguished between two modes of evaluation for sentences. In the normal, descriptive mode we first determine which proposition the sentence expresses; then we evaluate the resulting proposition as true or false. Interpretation precedes truth-evaluation. In the symbolic or hermeneutic mode, truth-evaluation takes place first: The sentence is assigned the value 'true' before interpretation. Arguably, that is what happens in our cases. The Lacanian sentence is believed to be true because it has been uttered by Lacan, who is believed to be a truth-teller. But the Lacanians who accept this sentence do not (yet) understand what it says, if indeed it says something. Similarly, the student accepts the sentence about synecdoches because she trusts the teacher who made the utterance, and she accepts it before understanding what it means.

${ }^{1}$ It is a striking fact that, among Lacanians, which interpretation is offered of a particular Lacanian dictum (such as 'The unconscious is structured like a language' or 'There is no sexual intercourse') does not really matter: the diversity of possible interpretations is admitted. The only thing which is sacrosanct and cannot be disputed is the belief that what Lacan says is true. 
In Sperber's later paper, 'Apparently Irrational Beliefs' (1985), the distinction

between the two modes of interpretation is cashed out in terms of a distinction between two ways of being stored in the mind - a distinction that was already present in Rethinking Symbolism. A representation, for example the sentence 'Turtles lay eggs', can be directly fed into the 'belief box', or it can be embedded within a metarepresentation which itself figures in the belief box. In the first case the representation interacts with other representations in the mind and this interaction yields action: mental action (inference) or bodily action caused by beliefs in conjunction with desires. In the meta-representational case the representation is insulated from other representations. Thus I can believe that John said that turtles lay eggs, without actually believing that turtles lay eggs: The sentence 'Turtles lay eggs' occurs in the belief box via the meta-representation in which it is embedded, but it does not occur in isolation, hence it does not give rise to a belief. It does not freely interact with the other representations in the belief box and the rest of the system.

An insulated representation can be emancipated, if the meta-representational frame within which it is embedded is a validating frame: a frame such as 'It is true that....' If we believe that it is true that turtles lay eggs, we are automatically justified in believing that turtles lay eggs. ${ }^{2}$ Sometimes, however, emancipation is blocked because the object-representation is semantically 'ill-formed'. That is what happens in quasibelief, according to Sperber: the representation which is embedded in a validating metarepresentation ('Lacan says that...' or 'The teacher says that...') is 'semi-propositional' and cannot be fully interpreted within the mental idiolect of the subject. Often this is

2 In the Port-Royal Logic we find an interesting analysis of validating metarepresentations like 'Aristotle said that the Earth is flat'. Two interpretations are distinguished: the meta-representational interpretation, in which the utterance says something about Aristotle; and another interpretation, in which the utterance says something about the Earth, under the authority of Aristotle (Arnauld \& Lancelot 1683: 167-8). A similar analysis has been offered by the French linguist Oswald Ducrot (Ducrot 1980: 44 ff; see also Ducrot 1984: ch. 7-8). 
because the embedded sentence itself contains some uninterpreted symbol. That a symbol is uninterpreted in this way (whether uninterpreted tout court or uninterpreted in the idiolect of the subject) can be indicated by putting quotation marks around it, as in: Cicero's prose is full of 'synecdoches'

Its containing an uninterpreted symbol prevents (1) from being fed into the belief box. Such a representation can only be entertained meta-representationally. One can have beliefs about a representation which one does not fully understand (e.g. one can believe that it is true), but that is all one can do with such a representation, according to Sperber. In order to give rise to a belief in the strict sense (a 'belief box belief', as he now says), a representation must be fully understood. I will call this 'Sperber's constraint'. ${ }^{3}$

Why should semi-propositional representations be prevented from going into the belief box? In 'Apparently Irrational Beliefs', Sperber gives an evolutionary argument in support of his constraint: there would be too great a risk of inconsistency if semipropositional representations were admitted into the belief-box (Sperber 1985: 54-5). Semi-propositional representations are not fully understood, hence we are unable to determine whether or not they are compatible with other representations in the belief box. ${ }^{4}$ To avoid contradictions, it is better to store in the belief box only representations which we fully understand, i.e. representations such that we can, in principle, check whether or not they contradict other representations in the belief box.

3 Arguably, that constraint goes back to Russell (1918: 218). In what follows I will always use 'belief' in the strict sense of 'belief box belief'.

${ }^{4}$ Suppose the semi-propositional representation that Cicero's prose is full of 'synecdoches' is fed into the belief box, where the representation that Cicero's prose contains no metonymies is already stored. And suppose that it turns out that synecdoches are a species of metonymies. A contradiction results. 
To sum up, quasi-belief involves two components, in Sperber's framework:

(i) the quasi-believer has a validating meta-belief, to the effect that a certain representation is true; yet

(ii) that representation cannot be emancipated and give rise to a plain belief, because it is 'semi-propositional'.

In what follows I will discuss three aspects of this treatment of quasi-belief. I will first consider the relation between quasi-belief and the validating meta-belief mentioned in (i). Is the quasi-belief identical to the meta-belief (as Donnellan 1993 suggests), or is it distinct from it and caused by it? In $\S 2$ I will argue in favour of the view that quasibelief cannot be reduced to meta-belief.

The second aspect I want to discuss concerns the content of the quasi-belief (§3). Sperber says that the primary object of quasi-belief (the representation which the quasi-believer accepts) is semantically indeterminate. I will argue that it need not be. Except in rather special cases, 'deferential' representations have both a determinate character and a determinate content. They are not semantically but epistemically indeterminate.

The third issue to be dealt with concerns Sperber's constraint. Is it true that the representations which are the object of quasi-belief are prevented from going into the belief box because they are not fully understood? More generally, is quasi-belief an attitude distinct from belief (in the strict sense), or is it merely a species of belief? I will discuss Sperber's most recent justification of his constraint, as well as his earlier evolutionary argument; both of them will be found wanting. Against Sperber, I will conclude that quasi-belief is a species of belief $(\S 4)$. 


\section{Quasi-belief and meta-belief}

Many philosophers think that the proper objects of propositional attitudes such as belief are 'propositions', construed either as sequences of semantic values (objects, properties, etc.) or as sets of possible worlds. If we take this line, we are almost irresistibly led to the view that quasi-belief is reducible to meta-belief, because of the following argument.

Genuine attitudes, on the propositionalist view, take propositions as contents. But in many instances of quasi-belief the object-representation (i.e., the half-understood representation the meta-belief is about) does not uniquely determine such a content. Hence there is no attitude whose content corresponds to that of the objectrepresentation. The only genuine attitude involved in such a case is the attitude whose content corresponds to the meta-representation; for the latter is fully propositional, in contrast to the object-representation. Now this attitude is, simply, belief: the quasibeliever believes the validating meta-representation (e.g. she believes that Lacan says that the unconscious is structured like a language). It follows that quasi-belief is nothing other than a certain type of meta-belief. As Donnellan suggests in a recent paper,

when the person in Burge's most well-known example says to the doctor, "I think I have arthritis in my thigh",... what is really believed is only that the speaker has in the thigh the condition called 'arthritis', or something like that. (Donnellan 1993: 167)

Another position is available, however. A growing number of philosophers think that the object of the attitudes - and the attitudes themselves - can be split in two. According to the representational theory of the mind, put forward in the seventies (e.g. Harman 1973, Fodor 1975, Field 1978), to believe that $p$ is to accept a representation $r$ which means that $p$. This suggests that there are two distinct relations at work: a primary relation (acceptance) between a cognitive agent and a representation, and a 
secondary relation (belief) between the agent and the proposition which the representation expresses. ${ }^{5}$ That theory, which takes representations to be the primary objects of the attitudes, has received considerable support from more recent studies concerning indexical belief and the puzzles of cognitive significance. As Perry has shown, the puzzles evaporate as soon as we draw a principled distinction between the accepted representation and the proposition thereby believed (Perry 1980, 1992). Thus a rational subject may believe and disbelieve the same thing, provided she does so under different 'modes of presentation', i.e. by accepting different representations.

Once we take the representationalist line and grant the dual aspect of the attitudes, it becomes possible to treat quasi-belief as a genuine attitude toward the object-representation, distinct from the attitude of belief toward the metarepresentation. What, according to Sperber, characterizes quasi-belief is the fact that the accepted representation does not uniquely determine a proposition (Sperber 1985: 51), either at the individual or at the public level. This is compatible with there being a genuine attitude toward that representation. Belief and quasi-belief can be construed as two attitudes towards representations - two varieties of 'acceptance':

- one believes that $p$ iff one accepts a representation which means that $p$;

- one quasi-believes that $p$ iff one accepts a representation whose meaning is partly indeterminate (in a sense to be discussed).

One good reason for maintaining the distinctness of quasi-belief as a psychological attitude is this. Among the data to be explained is the continuity between quasi-belief and belief. This continuity manifests itself in learning. In learning, quasibelief gradually turns into belief (Sperber 1985: 53). We start by quasi-believing something which the teacher tells us, but which we do not fully understand. Still, we have partial understanding, and this enables us to use the representation in reasoning

\footnotetext{
${ }^{5}$ In the early days of the Representational theory, those relations were not as clearly distinguished as they now are.
} 
and to establish connections between the semi-propositional representation which we accept and other things which we believe. Exploring those connections sometimes leads us to genuine understanding, hence to belief.

Consider the synecdoche example. In the representation (1), repeated here,

$$
\text { Cicero's prose is full of 'synecdoches' }
$$

only one symbol is partly 'unanalysed' (as Sperber puts it). We understand the representation, except for one particular constituent. Even that constituent we partly understand, however. For example we know that a 'synecdoche' is a trope, distinct from metaphor, irony, litote, and hyperbole. But we do not know exactly which trope it is. We may also be aware of a few examples of synecdoches which the teacher gave. From the general definition of a trope, plus the semi-propositional knowledge about 'synecdoches' (including the fact that such and such examples are examples of 'synecdoche'), plus propositional knowledge about other tropes, we may sometimes gather what a synecdoche is. As a result, the semi-propositional knowledge that a 'synecdoche' is a trope, and that Cicero's prose is full of 'synecdoches', becomes fully propositional: quasi-belief gives way to belief.

I do not see how we can account for this continuity without acknowledging a genuine attitude of 'acceptance without understanding' (quasi-belief). In the situation I have described, learning consists in manipulating a representation which one does not fully understand, up to the point where one understands it. We start by accepting a representation without understanding it; this attitude of acceptance leads us to use the representation in a certain way; and by so using the representation we end up understanding it. What makes learning possible is the use to which the representation is put, and that use itself depends on the initial attitude of acceptance which motivates it.

Could we say that what motivates our use of the representation in learning is 'nothing other than' the validating meta-belief? No: without an appropriate attitude toward the object-representation (rather than merely an attitude toward the meta- 
representation), there would not be the appropriate use of it which eventually makes understanding possible. This attitude is caused by the meta-belief, but it is distinct from it. When emancipation is possible the validating meta-belief (e.g. 'The teacher says that Frege died in 1925') causes the corresponding belief ('Frege died in 1925'). When emancipation is not possible, the validating meta-belief does not lose all causal power; it still causes acceptance of the half-understood representation. Acceptance, under such conditions, is what I call 'quasi-belief'.

\section{The deferential operator}

In $§ 2$ I stressed the dual nature of objects of thought. A primary attitude of acceptance, directed toward sentences, is involved both in belief and in quasi-belief. According to Sperber, the difference between belief and quasi-belief lies in the semantic status of the accepted sentence. To believe that $p$ is to accept a representation $r$ which is semantically determinate and expresses the proposition that $p$. In quasi-belief, according to Sperber, the accepted representation does not uniquely determine a proposition. The representation is partly uninterpreted - at least from an individualistic point of view.

There are two possible interpretations of Sperber's claim that the accepted representation is semantically indeterminate. When we accept a representation which expresses the proposition that $p$, that proposition is the 'content' of the representation. As Perry repeatedly stressed, the accepted representation also possesses a 'character' over and above its propositional content. The 'character' of a representation is that aspect of it which contextually determines its truth-conditional 'content' (Kaplan 1989); it functions as a mode of presentation for the proposition which the representation contextually expresses. Hence a representation can be semantically indeterminate in two different ways: either it has a determinate character but that character fails to determine a content (in the context at hand); or it lacks a determinate character in the first place. 
It is well-known that the character of a representation may fail to determine a content, in certain contexts. That is, it is possible for a representation to be endowed with a character but no content, if the context is inappropriate. If I say 'He is tall,' but the man I take myself to be demonstrating does not exist, no proposition is expressed, even though the uttered sentence has a definite character. Another example is Austin's (1975: 96-7):

He said I was to go to 'the minister', but he did not say which minister.

The speech act which (2) reports is 'rhetically' defective (i.e. defective at the content level $)^{6}$ because a particular constituent (viz. the definite description) is contextually uninterpretable. The quotation marks, here as in the synecdoche example, indicate that a constituent of the representation remains uninterpreted.

There is a clear difference between the Austinian example and the synecdoche example, however. In the Austinian example the relevant constituent remains 'uninterpreted' at the content level; the representation possesses a (phatic) meaning, but part of its (rhetic) content cannot be computed for lack of contextual information (viz. which minister the speaker is referring to). In the synecdoche case, it is less obvious that the representation possesses a determinate meaning. Compare (2) with (3):

He said that Cicero's prose is full of 'synecdoches', but he did not say what a synecdoche is.

In (2), the meaning of 'the minister' is clear, but its contextual application is unclear. As a result, there is an indeterminacy at the content level. In (3) it is the meaning itself which is unclear: the hearer does not know what 'synecdoche' means.

What I have just said suggests a radical interpretation of Sperber's claim concerning the semantic indeterminacy of the accepted representation, in quasi-belief.

\footnotetext{
${ }^{6}$ Austin's phatic/rhetic distinction corresponds to that between character and content.
} 
According to that interpretation, the accepted sentence includes a symbol which is not even interpreted at the character level.

Thus interpreted, Sperber's claim faces the following objection. The accepted representation is supposed to be mentally entertained; but it is hard to think of a symbol being mentally entertained without being 'interpreted' in some fashion or other. There is a sense in which all mental entertaining is 'interpretation'; hence it is not obvious that we can talk of mentally entertaining uninterpreted symbols. In contrast perhaps to what happens in external language, if a mental sentence is well-formed, it must possess a definite meaning - a character — even if it falls short of expressing a definite content. This may well be the intuition that underlies Sperber's constraint: a sentence cannot go into the belief box if it contains uninterpreted symbols. With this I wholeheartedly agree - I would even go farther: a sentence cannot make its way into the mind (whether into the belief box or elsewhere) if it contains uninterpreted symbols.

Because of this objection, I think we ought to reject Sperber's claim on its radical interpretation; that is, we should maintain that the sentences accepted by the quasi-believer are endowed at least with a character. But which character? What is the character of 'The unconscious is structured like a language'? What about even worse examples of quasi-belief in which it is pretty clear that the accepted sentences are virtually meaningless? Shall we maintain that they, too, have a character?

Even with respect to Burgean cases, we have difficulties specifying the character of the accepted sentence. What is the character of (1)? The sentence 'Cicero's prose is full of synecdoches' has a definite character in English, but that 'public' character is irrelevant. Remember what I said above: In order to be entertained, a mental representation must be endowed with a character. Now the character in question — that which a mental sentence must possess in order to be entertained must be accessible to the thinker: it must be a character which the subject herself grasps — an individualistic character. The public character of the sentence is not sufficient if the subject does not grasp it. 
Despite those difficulties, I think we can maintain that the accepted sentence is endowed with an appropriate character, both in Burgean and in Lacanian cases. The accepted sentence must be allowed to include a specific constituent which I call the deferential operator. The deferential operator $\mathrm{R}_{\mathrm{x}}(\mathrm{)}$ applies to a symbol $\sigma$ and yields a complex expression $\mathrm{R}_{\mathrm{x}}(\sigma)$ whose character is distinct from that of $\sigma$ (if $\sigma$ has one). The character of $\mathrm{R}_{\mathrm{x}}(\sigma)$ takes us from a context in which the speaker tacitly refers to a certain cognitive agent $x$ (which can be an individual or a community of users) to a certain content, namely the content which $\sigma$ has for $x$, given the character which $x$ attaches to $\sigma$.

In Burgean cases, the complex symbol $\mathrm{R}_{\mathrm{X}}(\sigma)$ has both a character and a content. What is special with the expression $\mathrm{R}_{\mathrm{X}}(\sigma)$ is that its content is determined 'deferentially', via the content which another cognitive agent, contextually referred to, attaches or would attach to $\sigma$ in the context of utterance. In (1)

(1) Cicero's prose is full of 'synecdoches'

the last constituent is a deferential symbol whose character is a function from contexts in which users of the symbol 'synecdoche' are being referred to, to the contents which the symbol 'synecdoche' has for those users. In the particular context in which we imagine this representation to be tokened, the relevant user (the $x$ who is being tacitly referred to) is the teacher; hence the symbol's content, in this context, is the content which the symbol 'synecdoche' has for the teacher. Which content it is, the student does not know; but he trusts the teacher and therefore quasi-believes the proposition, whatever it is, which the accepted sentence expresses.

In Lacanian cases the accepted sentence possesses a deferential character but the attempted deference fails: No user $x$ has the cognitive resources for determining the content of the term to which the deferential operator applies, hence no content is expressed, in that context. Such failure occurs whenever a term is used deferentially by everybody, in a mutual or circular manner. 
In each type of case we must draw a distinction between (i) the character, if any,

of the symbol $\sigma$, and (ii) the character of the deferential symbol $\mathrm{R}_{\mathrm{x}}(\sigma)$. In Burgean

cases $\sigma$ has a public character, which the subject does not grasp; but the sentence which the subject accepts contains the deferential symbol $\mathrm{R}_{\mathrm{x}}(\sigma)$, whose character she grasps. In Lacanian cases $\sigma$ may well be publicly meaningless: the only character available in the linguistic community is that of the deferential symbol $R_{x}(\sigma)$. The subject does not grasp the character of $\sigma$, because there is no such character for her to grasp. What she grasps is the character of the deferential symbol.

Since the content of the deferential symbol $\mathrm{R}_{\mathrm{X}}(\sigma)$ is that which the character of $\sigma$ itself determines, $R_{x}(\sigma)$ has a content only if $\sigma$ has a character. It follows that, in Lacanian cases, the accepted sentence expresses no definite content. In Burgean cases it does: a determinate content is expressed, even though it is unknown to the quasibeliever. Thus the speaker who utters (4)

$$
\text { I have 'arthritis' in the thigh }
$$

expresses the proposition that she has arthritis in the thigh, even if she does not know what arthritis is (Burge 1979, 1982). Her use is deferential. In the same way, the student accepts a representation, viz. (1), which by virtue of the semantics of the deferential operator, expresses the proposition that Cicero's prose is full of synecoches.

On this view, the object of acceptance in quasi-belief is not a semi-propositional representation (i.e. a representation incompletely interpreted, at whatever level) but a deferential representation (i.e. a representation containing the deferential operator). Hence we must not only reject Sperber's claim on its radical interpretation (according to which the accepted sentence lacks a determinate character), but also on its weaker interpretation (according to which the accepted sentence lacks a determinate content). ${ }^{7}$ In Burgean cases the deferential representation has both a character and a content.

\footnotetext{
7 Sperber himself sometimes talks of the 'proper interpretation' of the semipropositional representation.
} 
Sperber's intuition of indeterminacy can still be captured, however. Even when

they have both a character and a content, deferential representations, though semantically determinate, are epistemically indeterminate: the quasi-believer does not know which proposition the deferential sentence she accepts expresses. Sperber's claim concerning semi-propositionality can therefore be construed as a claim concerning the epistemical state of the user, rather than a claim about semantic content.

\section{Quasi-belief is belief}

Beside the question, whether or not a determinate proposition is expressed (in Burgean cases), there is a further question: whether that proposition can be believed. The two issues are orthogonal. One can side with Burge and argue that a definite proposition is expressed, while simultaneously holding, with Sperber, that that proposition, being deferentially expressed, cannot be 'believed' in the strict sense of the term. The first question is semantic, the second psychological. It is the psychological question which we must now answer.

Sperber is a 'dualist': he holds the view that belief and quasi-belief are two distinct (if related) attitudes. As he puts it, 'There are at least two cognitively distinct manners of holding true', corresponding to belief and quasi-belief (this volume, p.00). To believe that $p$ is to have in one's belief box a representation which means that $p$. When someone quasi-believes that $p$, she does not have such a representation in her belief box. What she has in her belief box is a meta-representation about the accepted representation. It is possible to follow Sperber on this even if one opts for the deferential analysis sketched in $\S 3$. According to that analysis, deferential representations may well express determinate propositions. Still, one might hold that such representations cannot go into the belief box. Sperber's constraint, to the effect that whatever is believed must be fully understood, implies that deferential representations (insofar as they are epistemically indeterminate, i.e. not fully understood) cannot give rise to beliefs in the strict sense. They can be accepted but cannot be believed. 
Sperber's constraint, and Sperber's evolutionary argument for it, can easily be restated in the deferentialist framework. Deferential representations are highly risky: the believer has no control over which proposition is expressed, and inconsistencies can proliferate. Hence the policy of banning deferential representations from the belief box can only be profitable to the cognitive system.

What are we to think of this argument? Clearly, it presupposes Cartesian individualism. Sperber assumes that cognitive agents have their beliefs under control, in the sense that they know what they believe. Deferential representations are banned from the belief box precisely because, in their case, the subject does not know the semantic content of the representations which she accepts. But there is a clear sense in which cognitive agents do not, in general, 'know' the propositional contents of the representations which they accept: that is the lesson of externalism. There is nothing exceptional about deferential representations, in that respect. As research on cognitive significance has shown, whenever the accepted representation is indexical, or includes a name-like constituent, there is a possibility of referential mistake and/or lack of understanding. So the basis of Sperber's argument — cognitive individualism — is extremely shaky.

There is another objection to the claim that deferential representations are banned from the belief box. In $\S 2$, following Sperber himself, I stressed the continuity between quasi-belief and ordinary belief. This continuity suggests that deferentiality is a matter of degree. Instead of a sharp demarcation of ordinary beliefs from quasibeliefs, as that which results from Sperber's constraint, we should rather posit a continuum of cases.

In his most recent contribution to the topic (this volume) Sperber gives another argument in favour of his dualist position. I call it the argument from expressibility. It is a better argument than the evolutionary argument above, but, I will argue, it presupposes a semantic analysis which there is no particular reason to accept.

Let us start with a quotation from Sperber (this volume, p. 00): 
To accept the existence of a data-base [a belief box] is to assume some representational capacity by means of which data are represented in the data base. I will, for expository purposes, describe this capacity as a language of thought, a 'mentalese', and I will focus on the conceptual repertoire, the lexicon of this mentalese.

The mental lexicon must have limits, Sperber goes on to argue, hence there must be contents which cannot be (directly) expressed using that lexicon, because we lack the appropriate concepts. Contents which can be expressed using the basic conceptual repertoire are called 'intuitive'; contents which cannot are said to be 'non-intuitive'. In quasi-belief, according to Sperber, the content to which a credal attitude is directed is non-intuitive. That content cannot be articulated within the mental vocabulary of the cognitive agent: but the agent can express it indirectly via a process of semantic ascent. To that effect she has to use some mental place-holder for the unavailable concept some uninterpreted symbol $\sigma$. The resulting representation, including the place-holder, is semantically ill-formed (incomplete), hence it cannot go into the belief box; but the agent can embed it into a validating meta-representation. As the object-representation cannot be disquoted (because it does not have the right semantic format and includes a dummy symbol $\sigma$ ), no genuine belief is generated, but instead there is a quasi-belief: a validating meta-representation is believed but emancipation is blocked.

On this view dualism is true a priori. The belief box is defined as a repository for the outputs of a certain representational capacity: what exceeds that capacity (nonintuitive representations) cannot go into that box, by definition.

There is a prima facie difficulty for Sperber's position. How is it possible for a meta-representation to be fully interpreted when the object-representation itself is partly uninterpreted? Sperber apparently thinks that prefixing 'It is true that' (or 'Lacan believes that') to a semantically indeterminate representation can yield a semantically determinate meta-representation. It is hard to see how this view can be compatible with Semantic Innocence. If Semantic Innocence holds, the semantic incompleteness of the 
object-representation can hardly fail to entail the semantic incompleteness of the metarepresentation (see e.g. Prior 1976: 153-54).

Sperber could reply that Semantic Innocence applies to 'oblique' constructions such as 'It is true that ...' or 'Lacan says that...', but not to direct quotation. Thus, if 'glive' is a non-word and 'John kept gliving' is ill-formed, 'It is true that John kept gliving' (or 'Lacan said that John kept gliving') is bound to be ill-formed too; but the direct quotation 'Lacan said: "John kept gliving"' is well-formed. ${ }^{8}$ Since quotation marks can turn non-words into words in this manner, why not accept that there are mental quotation marks? That is, in effect, Sperber's suggestion. That suggestion is quite compatible with my analysis of quasi-belief in terms of the deferential operator. Even if a symbol $\sigma$ is unavailable to the quasi-believer, the deferential symbol $\mathrm{R}_{\mathrm{X}}(\sigma)$ is conceptually available. The deferential operator makes a concept out of an empty symbol.

Still, I find Sperber's new argument for his constraint unacceptable. According to Sperber's argument, the only representation which can go into the belief box is the meta-representation, for the object-representation is ill-formed. This argument presupposes that in quasi-belief there are only two representations available: the objectrepresentation, which is ill-formed and cannot go into the belief box, and the metarepresentation, which includes that object-representation in quotes and which is wellformed. But that assumption is unwarranted. Arguably, there are three distinguishable representations in the type of case we are considering. There is the 'disquoted' representation including some uninterpreted symbol; the 'deferential representation' including that symbol in quotes (that is, in the scope of the deferential operator); and the meta-representation in which the deferential representation can be embedded, and which contains some explicit reference to the cognitive agent (or the community of users) to whom the subject defers.

\footnotetext{
8 The same thing holds for 'Lacan said that John kept "gliving"', which is a mixture of oblique construction and direct quotation.
} 
Let us go back to the synecdoche example. The three-prong distinction I am trying to make is that between (1a), (1b) and (1c):

(1a) Cicero's prose is full of synecdoches

(1b)Cicero's prose is full of 'synecdoches'

(1c) The teacher said that Cicero's prose is full of 'synecdoches'

In a cognitive system which lacks the concept of synecdoche, (1a) is unexpressible (non-intuitive), hence it cannot be 'believed.' Thus far I follow Sperber. But Sperber argues from there that the only belief there is is meta-representational: it is a belief corresponding to (1c). I agree that a meta-belief like (1c) is in the belief box, in most instances of quasi-belief; but I deny that that is the only belief there is in the quasibelief situation. (1b) corresponds to the third representation available: the deferential representation itself, including materials 'in quotes'. That representation is distinct both from the ill-formed object-representation (1a) and from the meta-representation (1c). In contrast to (1a), it is well-formed (since the dummy symbol occurs 'in quotes'), hence it can go into the belief box. In contrast to (1c), it is meta-representational only at the character level: the content of the deferential representation (1b) is not metarepresentational.

Deferential representations are meta-representational at the level of character but not at the level of content. As an analogy, consider the pronoun 'I'. As Reichenbach pointed out, the meaning of token-reflexive expressions like 'I' is meta-representational — it conveys an implicit reference to the expression itself (Reichenbach 1947). 'I' means: 'the person who utters this utterance'. But the proposition expressed by 'I am bald' is not meta-representational. That is because 'I' is directly referential: its metarepresentational character determines its content but is not part of it (Kaplan 1989). In the same way, I construe deferential symbols as directly referential. The semantic value of $\mathrm{R}_{\mathrm{X}}(\sigma)$ is the semantic value which $\sigma$ has for $x$. That semantic value is the content of $\mathrm{R}_{\mathrm{x}}(\sigma)$. The meta-representational reference to $x$ 's use of $\sigma$ is not part of the content of $\mathrm{R}_{\mathrm{x}}(\sigma)$ : it contextually determines that content. 
Sperber does not acknowledge the existence of the deferential representation (1b). He recognizes only two representations: the ill-formed object-representation (1a), and the meta-representation (1c) in which it is embedded in quotes. For Sperber, (1c) is not analysed as

The teacher believes that + Cicero's prose is full of 'synecdoches'

but as:

The teacher believes that...'..' + Cicero's prose is full of synecdoches

He considers the quotes around the non-word as necessarily part and parcel of a complex meta-representational frame such as that of (1c). That is precisely what I am denying. I think the deferential operator can appear in simpler representations like (1b) — no well-formedness constraint rules out such simple deferential representations. If I am right, deferential representations such as (1b) need not be embedded into an explicit meta-representational frame such as (1c) in order to go into the belief box. 'Simple' deferential representations are semantically well-formed and can go into the belief box on their own.

To be sure, a simple deferential representation such as (1b) makes sense only 'in the context of meta-representations such as (1c). But that dependence of simple deferential representations on associated meta-representations can be treated by construing the deferential operator as 'indexical', that is, as constraining the context in which it is tokened. There is a constraint on the use of a deferential symbol such as $\mathrm{R}_{\mathrm{X}}(\sigma)$ : the user of $\mathrm{R}_{\mathrm{X}}(\sigma)$ must entertain appropriate meta-representational attitudes, viz. the belief that some agent $x$ uses $\sigma$ with a certain content, and the intention to use $\mathrm{R}_{\mathrm{X}}(\sigma)$ with precisely that content. The deferential symbol expresses a determinate content only if that constraint is contextually satisfied. For it to be satisfied, there must be some meta-representation like (1c) in the belief box. Still, (1b) also occurs in the belief box as a separate representation. Appropriately using a deferential representation implies 
having a meta-belief, but the deferential representation is otherwise independent of the meta-representation: it is well-formed in its own right (as an indexical sentence is wellformed), and its content is distinct from the content of the meta-representation. ${ }^{9}$

In this framework, what is prevented from going into the belief box is not the deferential representation, including the place-holder $\sigma$ in the scope of the deferential symbol R(), but the 'disquoted' representation which results from emancipating $\sigma$. The deferential representation itself can go into the belief box. Since that is so, there is no reason to deny that quasi-beliefs are beliefs. The person who quasi-believes that $p$ has, in her belief box, a certain representation (the deferential representation) expressing the proposition that $p$. If to believe that $p$ is to have in one's belief box a representation which means that $p$, then the person who quasi-believes that $p$ believes that $p$.

\section{Postscript}

In the first version of this paper, which I wrote after the Caen conference and presented at CREA in December 1995, my main target was Sperber's notion that quasi-beliefs are semantically indeterminate and can be described as the acceptance of a 'semipropositional representation'. I put forward an alternative account in terms of the 'deferential operator' (see $\S 3$ above). In the discussion following the deliverance of the paper, another focal issue emerged: Sperber's 'dualism', i.e. his view that in quasi-belief the accepted representation is not stored directly in the belief box, hence does not qualify as a belief in the strict sense of the term, came under attack. Ned Block, in particular, expressed his skepticism so convincingly that, in revising the paper, I added a section criticizing Sperber's dualism (§4). In his paper 'Concepts, Beliefs, and MetaRepresentations', written shortly after the discussion of my paper, Sperber himself

9 (1b) deferentially expresses the proposition that Cicero's prose is full of synecdoches (i.e. the proposition which (1a) would express in the mouth of the teacher). That content is very different from the meta-representational content of (1c). 
addressed the issue and criticized the anti-dualist position (which he calls 'disquotational incontinence'). It is that paper which is published in revised form in this issue, under the title 'Intuitive and Reflective Beliefs'.

After reading the final versions of our respective papers, I have the feeling that the debate concerning dualism is obscured by terminological clouds. Sperber now systematically uses 'belief' in what he calls 'the ordinary somewhat loose sense of the term' (p.00), even though he holds that belief in that sense is not a genuine category but covers two very different sorts of things. I, on the contrary, use 'belief' in the strict sense: there is belief whenever a representation is stored in the 'belief box' in such a way that it can be freely used in practical or theoretical inference. This is obviously confusing, and Sperber himself appears to have been confused; for he misleadingly suggests that we agree that quasi-belief is belief (p.00). But we don't agree: he holds that quasi-belief is belief in the ordinary, loose sense - something which of course I accept — but he denies what I hold, namely: that it is a species of belief in the strict sense.

Another terminological problem arises from Sperber's shifty use of 'intuitive' in the new version of his paper. At least two senses of 'intuitive' can be distinguished:

- In a first sense, a belief is 'intuitive' if and only if it is (or could be) the output of perceptual processes or of spontaneous and unconscious inferential processes taking ultimately perceptual beliefs as premisses. Deferential beliefs (quasi-beliefs) are not intuitive in that sense; they essentially depend on communication.

- In the second sense, a belief is 'intuitive' if and only if, in order to hold it as belief, you need not reflect on the way you arrived at it, or on the specific justification you may have for holding it. It is a belief which you might keep holding even if you forget how you arrived at it. 
The two senses are clearly distinct. I take it to be possible for an ill-understood, deferential representation (a representation which is 'non-intuitive' in the first sense) to be stored into the belief box as a result of communication, and to remain there, even though the subject has come to forget the communicational source of the belief and the justification she originally had for holding it. This does not mean that the belief is no longer justified: The fact that the subject has that belief (i.e. the fact that the representation is stored in her belief box) may be considered as sufficient justification for continuing to hold it, in the absence of appropriate counter-evidence.

Sperber's use of 'intuitive' is shifty because he thinks the two senses are extensionally equivalent; and he thinks that because of his mistaken belief that deferential representations cannot be detached from meta-representations. Since I hold that, in quasi-belief, the deferential representation is autonomous - in the sense that it can be tokened without necessarily tokening the meta-representation from which it has originally been detached - I do not see why some beliefs could not be intuitive in the second sense and, at the same time, non-intuitive in the first sense. In any event, whether there actually are beliefs with this complex property (intuitive in the second sense and non-intuitive in the first sense) is an empirical issue, contrary to what Sperber suggests in his paper.

\section{References}

Arnauld, A. and P. Nicole (1683), La Logique ou l'Art de penser. Paris: Guillaume Desprez.

Austin, J.L. (1975), How to Do Things with Words, 2nd ed., Oxford:

Clarendon Press. 
Burge, T. (1979), Individualism and the Mental. Midwest Studies in Philosophy 4: 73121.

Burge, T. (1982), Other Bodies. In A. Woodfield, ed., Thought and Object, Oxford: Clarendon Press, p. 97-120

Donnellan, K. (1993), There is a word for that kind of thing: an investigation of two thought experiments. Philosophical Perspectives 7: 155-71.

Ducrot, O. (1980), Analyse de texte et linguistique de l'énonciation. In O. Ducrot et al., Les Mots du Discours, Paris: Minuit, p. 7-56.

Ducrot, O. (1984), Le Dire et le Dit, Paris: Minuit.

Field, H. (1978), Mental representation. Erkenntnis 13: 9-61.

Fodor, J.A. (1975), The Language of Thought. New York: Crowell.

Harman, G. (1973), Thought. Princeton: Princeton University Press.

Kaplan, D. (1989), Demonstratives. In J. Almog, H. Wettstein and J. Perry (eds.),

Themes from Kaplan, New York: Oxford University Press, p. 481-563.

Perry, J. (1980), Belief and Acceptance. Midwest Studies in Philosophy 5: 533-42.

Perry, J. (1992), The Problem of the Essential Indexical and Other Essays. New York: Oxford University Press.

Prior, A. (1976), Papers in Logic and Ethics. London: Duckworth. 
Reichenbach, H. (1947), Elements of Symbolic Logic. New York: Macmillan.

Russell, B. (1918), Knowledge by Acquaintance and Knowledge by Description. In Mysticism and Logic and Other Essays, London: Longmans, Green and Co, p. 209-32.

Sperber, D. (1975), Rethinking Symbolism. Cambridge: Cambridge University Press.

Sperber, D. (1985), Apparently Irrational Beliefs. Chapter 2 of On Anthropological Knowledge, Cambridge: Cambridge University Press.

Sperber, D. (1997), Intuitive and Reflective Beliefs. This volume, p. 00-00. 